\title{
Working
}

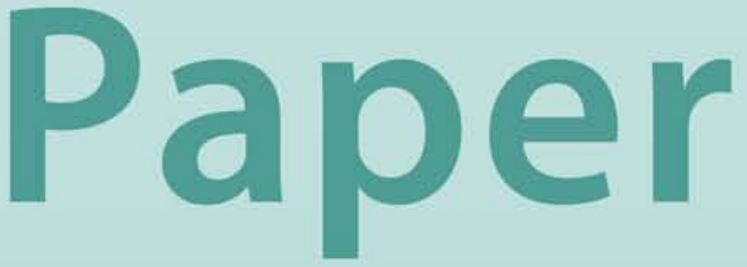




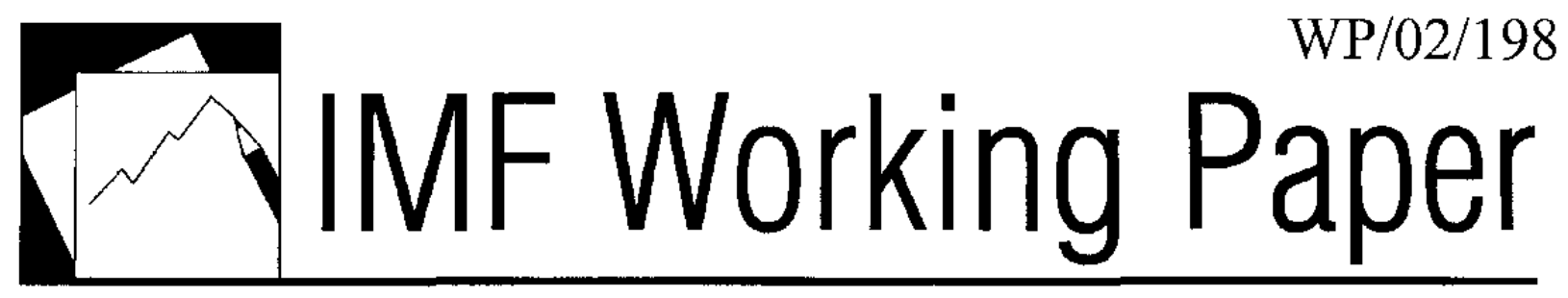

The Economics of Post Conflict Aid

\author{
Dimitri G. Demekas, Jimmy McHugh, \\ and Theodora Kosma
}




\title{
IMF Working Paper
}

\author{
European I Department
}

\section{The Economics of Post Conflict Aid}

\author{
Prepared by Dimitri G. Demekas, Jimmy McHugh, and Theodora Kosma ${ }^{1}$
}

November 2002

\begin{abstract}
The views expressed in this Working Paper are those of the author(s) and do not necessarily represent those of the IMF or IMF policy. Working Papers describe research in progress by the author(s) and are published to elicit comments and to further debate.
\end{abstract}

Post conflict aid is different from conventional development aid and has different effects on the recipient economy. The paper builds a theoretical model tailored around the main stylized facts of post conflict aid and traces the impact of different kinds of post-conflict aid on capital accumulation, growth, welfare, and resource allocation. While both humanitarian and reconstruction aid are welfare-enhancing, humanitarian aid reduces long-run capital accumulation and growth. Reconstruction aid, on the other hand, may increase the long-run capital stock and, if carefully designed, avoid the pitfalls of the Dutch disease.

JEL Classification Numbers: F35, 019, 041

Keywords: aid, reconstruction, humanitarian assistance, post conflict

Authors' E-Mail Addresses: ddemekas@imf.org.jmchugh@imf.org,kosma@aueb.gr

\footnotetext{
' Advisor, European I Department, IMF; IMF Resident Representative in Armenia; and Athens University of Economics and Business, respectively. Theodora Kosma was a Summer Intern at the IMF when this paper was written. The authors are grateful to Javier Hamann and the participants at an IMF seminar in August 2002 in which a first draft of this paper was presented, but remain responsible for all errors.
} 
I. What is Special About Post Conflict Aid? .......................................................

II. The Received Wisdom on the Effects of Foreign Aid .............................................. 5

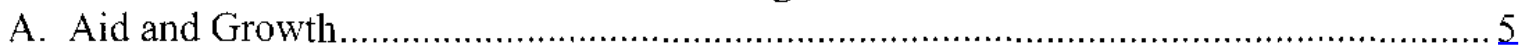

B. Aid and Resource Allocation .................................................................... 7

III. The Economics of Post Conflict Aid ............................................................................

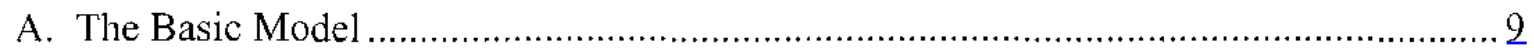

B. The One-Good Variant ............................................................................. 10

C. The Two-Good Variant ................................................................................ 14

IV. Conclusions and Lessons for Aid Donors ............................................................. 20

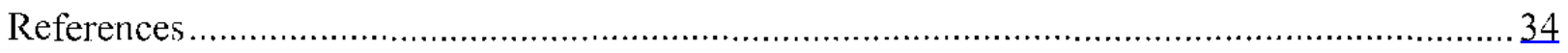

Tables

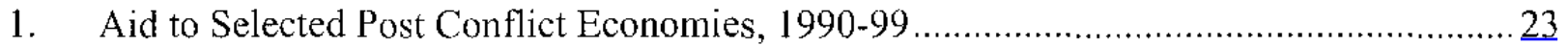

2. Overall Assistance to South Eastern Europe by Type (1999-2001) ..............................24

3. South Eastern Europe - The Stability Pact Quick Start Package ...................................25

Appendices

1. Proof of Saddle-Point Equilibrium of the One-Good Dynamic System ........................26

2. The Impact of $\alpha$ on the Steady State Equilibrium..................................................27

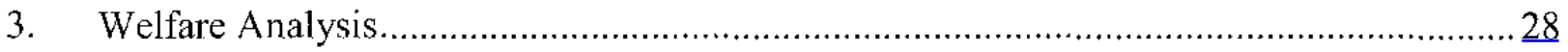

4. The Impact of $R$ on Resource Allocation............................................................... 33 


\section{What is Special About Post Conflict Aid?}

Post-conflict aid is different from conventional development aid. The most obvious difference stems from the stark environment into which post conflict aid is disbursed. Conflict creates humanitarian catastrophes, destroys infrastructure and institutions, and displaces labor. During conflict, investment and savings decisions are disrupted and distorted. Conflict redirects economic activity towards rent-seeking and criminality, while productive activity is suppressed. ${ }^{2}$ Of course, conventional development aid is also disbursed in difficult circumstances sometimes. But the magnitude of these problems in post conflict countries is much greater.

In these circumstances, post conflict aid has two main objectives. First, donors strive to address the humanitarian emergency that often follows violent conflict, providing shelter to displaced people and ensuring minimum levels of consumption to those unable to fend for themselves. This is the humanitarian objective. Second, donors try to repair or rebuild the destroyed infrastructure, such as roads, waterways, energy and communications networks, as well as restore the provision of basic public services that were disrupted by the conflict, such as security, law enforcement, and public health. This is the reconstruction objective. In contrast, while partly encompassing some of these objectives, the main goal of development aid is to supplement domestic savings, boost long-term investment and growth, and reduce poverty.

This distinction explains some of the unique characteristics of post conflict aid. Post conflict aid can reach extraordinarily high levels, both in per capita terms and relative to the size of the recipient economy, but typically declines very rapidly once the emergency phase is over. A few examples can illustrate this pattern. In the case of post-civil war Rwanda, foreign aid flows reached a staggering 95 percent of GDP in 1994, but declined to under 20 percent within five years. In Bosnia \& Herzegovina, aid flows reached almost 75 percent of GDP after the end of the war in 1994 , but fell to less than 25 percent by 1999 (Table 1). In Kosovo, foreign aid reached an estimated 65 percent of GDP immediately after the end of the war in 1999 , but is expected to fall to 10 15 percent by 2004 (Demekas et al. 2002). In contrast, conventional development aid fluctuates much less and at much lower levels: official development assistance to the group of low income countries ranged between $2 \frac{1}{2}-3$ percent of gross national income

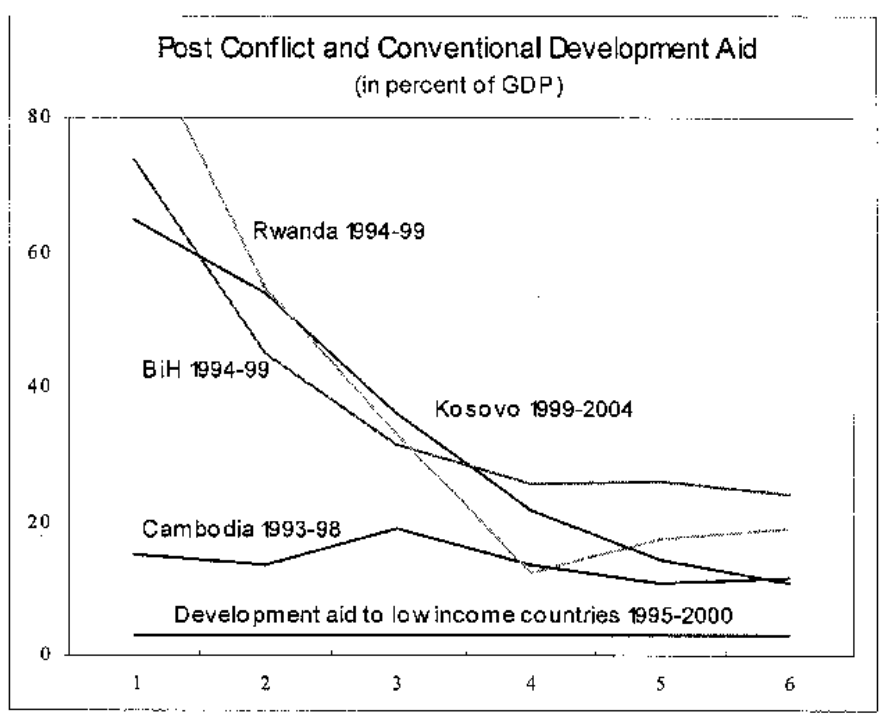

${ }^{2}$ There is surprisingly little research on the economic consequences of conflict and war. One recent example is Collier (1999). 
during 1995-2000 (World Bank, 2001). To put it starkly: post conflict aid comes in a large sudden burst while, compared to that, development aid is a steady trickle.

In addition to its size and time profile, the composition of post conflict aid is also distinctive. The humanitarian and reconstruction components of post conflict aid are clearly separate and evolve in different ways. The experience of South Eastern Europe in the wake of the 1999 Kosovo crisis highlights these differences. Between 1999 and 2001, the international community committed around $€ 6$ billion a year to the economies of South Eastern Europe. ${ }^{3}$ In the immediate aftermath of the Kosovo conflict, a large part of this package (around $€ 1.3$ billion in 1999) was allocated to humanitarian assistance. As the humanitarian crisis abated and most refugees started returning home, humanitarian assistance declined drastically (to just over $€ 0.4$ billion in 2001). At the same time, however, the amount of reconstruction aid almost doubled (Table 2). Unlike humanitarian aid, reconstruction aid directly contributes to the rehabilitation and improvement of the productive capacity of the economy.

Not all reconstruction aid is for repairing physical capital and infrastructure. A significant part represents institution-building efforts, such as re-establishing or reinforcing the basic legal framework for private sector development, strengthening the judiciary, introducing modern regulation and building supervisory agencies, opening regional trade links, and establishing a tax system and tax administration. Table 3 provides additional information on the composition of post conflict aid to South Eastern Europe (in particular, of the fast-disbursing "quick-start" package): a full third of this assistance was dedicated to institution-building activities and regional cooperation. These intangible services are at least as important as the physical infrastructure for the economic recovery of post conflict countries and regions.

These characteristics (circumstances, objectives, size, time profile, and composition) make post conflict aid special. Our central hypothesis is that the traditional analytical tools developed in order to examine the impact of conventional development aid are not appropriate for the study of post conflict aid. In addition, one cannot help noticing that the traditional aid literature has for some time now been in crisis: empirical research has been unable to find convincing evidence that development aid is indeed effective in promoting growth; there is even disagreement on the conditions under which development aid can be effective. In our view, this strengthens the case for a fresh look at the way we think about aid.

In this paper, we develop a theoretical model that departs from the traditional aid literature and attempts to incorporate the main stylized facts about post conflict aid. We then use it to trace the impact of post conflict aid--and its different components-on capital accumulation, growth, welfare, and resource allocation. The following Chapter summarizes what we know about the impact of aid from the traditional aid literature; Chapter III presents our basic model and two variants; and Chapter IV draws the policy implications of our findings.

${ }^{3}$ Albania, Bosnia \& Herzegovina, Bulgaria, Croatia, Federal Republic of Yugoslavia (FRY), Kosovo-FRY, FYR Macedonia, Moldova, and Romania. 


\section{The RECEIVED Wisdom On THE EFFECTS OF Foreign AID}

There is an extensive literature on the effects of foreign aid on the recipient economy, tracing its origins back to the discussion of the "transfer problem" (Keynes, 1929; Ohlin, 1929; Pigou, 1932). The two main strands are those that focus on the impact of aid on growth and on the impact of aid on resource allocation (the latter related to the "Dutch disease" literature).

\section{A. Aid and Growth}

Historically, the rationale for aid has its theoretical foundations in the Harrod-Domar model, in which the driving force of economic growth is physical capital formation. In low-income countries that may be unable to save enough to finance high investment, foreign aid provides an additional source of funds that closes the domestic savings gap, boosts investment, and ultimately leads to higher growth. A variant of this model incorporates the additional assumption that (most) capital goods are not produced domestically but are imported, thereby linking investment and imports. If exports are not sufficient to finance the necessary level of capital goods imports, investment and growth suffer. Again, foreign aid helps close this trade gap and leads to higher growth.

This so-called "aid-investment-growth" hypothesis provided the intellectual foundation on which a huge aid industry was built after World War II in developed countries. Unfortunately, despite extensive efforts to provide empirical support for this hypothesis - much of it expended by international organizations involved in the aid business - the results were disappointing: there does not seem to be conclusive evidence of a robust link between foreign aid and growth.

This empirical literature has followed two tracks (White, 1992; Hansen \& Tarp, 2000; and Hjertholm et al., 2000 provide excellent surveys). A large number of studies attempted to measure directly the impact of aid on growth, typically through reduced-form regressions, with very poor results: aid is sometimes found to have a positive impact on growth, but very often its impact is insignificant or negative. A number of other studies tried to examine the indirect link between aid and growth through investment. Once again, the evidence is inconclusive. While earlier papers generally found a positive correlation between aid and investment, more recent studies were unable to establish such a link (see Easterly, 1999; Dollar \& Easterly, 1999). ${ }^{5}$

\footnotetext{
${ }^{4}$ Referring to the reparations imposed by the Versailles Treaty on Germany at the end of WWI.

5 In the context of the so-called "fiscal response" literature, which tries to gauge the response of fiscal policy to aid flows, there have also been attempts to examine the impact of aid specifically on public investment. Gang and Khan (1991), Otim (1996), and McGillivray (2000), among others, find that aid tends to increase public investment, especially if it is linked to specific public investment projects. However, by relaxing the government budget constraint, aid may also diminish the tax effort. Otim (1996) finds that foreign aid tends to strengthen the government's tax effort, but McGillivray (2000) is unable to establish a statistically significant relationship.
} 
Efforts to incorporate aid in a structural growth model had similarly ambiguous results. A number of studies (e.g., Obstfeld, 1999; Gong \& Zou, 2001) introduce foreign aid in an optimal growth model, treating it as a lump-sum transfer that changes the representative agent's budget constraint. As the representative agent maximizes intertemporal utility under the expanded budget constraint, the impact of aid on the optimal consumption and capital accumulation paths can be traced. In these studies, aid has generally been found to stimulate investment in the short term. In the long term, however, aid lowers the steady state capital stock, increases consumption, and reduces labor supply.

Against this background, the focus recently started shifting to the reasons behind the apparent ineffectiveness of foreign aid. One strand of this literature concentrates mainly on the interaction between foreign aid and the policy environment. Burnside \& Dollar (2000) argued that aid is often disbursed in the presence of serious policy distortions that reduce the marginal productivity of capital and weaken the incentive to invest. In such environments, aid is more likely to be consumed than invested. Burnside \& Dollar tested their hypothesis by including a range of institutional and policy indicators along with aid in a reduced-form growth regression, and found that aid is more effective in countries with good policy environments. In a similar vein, Dollar \& Easterly (1999), while unable to detect a relationship between aid and investment in general, claimed that there is a statistically significant relationship between aid and investment in good policy environments. These papers were initially very influential: they were seen as the answer to the "paradox" of the ineffectiveness of foreign aid. But Hansen \& Tarp (2000 and 2001) have undermined these results, showing that they are extremely data dependent and, on the basis of the available evidence, concluded that the policy environment in the recipient country does not affect the effectiveness of aid.

Even if the policy environment matters, it is just one of several determinants of the effectiveness of aid. Lensnik and Morrisey (2000) argued that aid instability adversely affects investment decisions. In countries where aid is a major source of public revenues, McGillivray \& Morrissey (2001) showed that volatility of aid flows can induce fiscal behavior that hinders growth (directly through cuts in public investment and indirectly through the complementarities between public and private investment). Bulír \& Hamann (2001) confirmed these findings and, analyzing data for over 100 aid recipient countries, showed that uncertainty about aid disbursements is large and that the information content of donor commitments is very small indeed.

This extensive literature on the impact of aid on growth is based on the experience of developing economies. Aid is modeled as an income transfer that relaxes the budget constraint of the recipient. The characteristics of the recipient economy are not taken into account, and no attempt is made to distinguish between different kinds of aid. Furthermore, with very few exceptions, the aid flow is implicitly assumed to be permanent (or last indefinitely), and no attempt is made to model the impact of a temporary transfer that depends on the state of the recipient economy. ${ }^{6}$ As

\footnotetext{
${ }^{6}$ One exception is Gong \& Zou (2001), who examine the impact of a temporary transfer of consumption goods, and find that it has no long-run impact but only influences the transitional
} 
we saw carlicr, however, the facts in post conflict economies are completely different. Post conflict aid typically includes large amounts of humanitarian assistance that is tied to the needs of the country and tends to lapse once the emergency is over; and funds for reconstruction of destroyed infrastructure and for institution-building contribute directly to the rehabilitation of the productive capacity. Taken together, these transfers can reach extraordinarily high levels in the early post-conflict years, but decline rapidly thereafter. These differences in the nature, size, composition, and time profile of aid between post conflict and developing countries suggest that the findings of the traditional aid literature may not apply in post conflict cases.

\section{B. Aid and Resource Allocation}

Another important strand of the aid literature examines the impact of foreign aid on the recipient economy. Michaely made one of the earliest contributions in this area (Michaely, 1981). He used a simple two-sector model with tradable and non-tradable goods, in which foreign aid is introduced as a transfer of tradable goods. As the relative price of non-tradables increases in order to restore equilibrium, resources move to that sector and the production of tradables falls while that of non-tradables increases. In this model, the impact of aid is similar to the so-called

Dutch disease. ${ }^{7}$ In a similar vein, Van Wijnbergen (1986) pointed out that the contraction of the tradable goods sector caused by aid hinders the export promotion objectives of many aid programs (see also the surveys in Rattsø \& Torvik, 1999, and Hjertholm et al., 2000). These results aggravated the consternation among aid advocates: not only did the link between aid and growth turned out to be at best tenuous, but aid could directly hamper the country's ability to reach and maintain a sustainable external position.

To make matters worse, the Dutch disease literature seemed to suggest that the damage to the tradable goods sector may be permanent even if the aid flow is temporary. Krugman (1987) pointed out that in the presence of learning-by-doing effects (or more generally increasing returns to scale) in the tradable goods sector, the future productivity in this sector would depend on its cumulative output. Consequently, even a temporary contraction in the output of the tradable goods sector triggered by a lump-sum foreign exchange transfer-such as aid-could lead to a permanent reduction in the productivity of this sector.

As in the case of the literature on the impact of aid on growth, these studies do not quite fit the experience of post conflict economies. Aid is modeled simply as a transfer of tradable goods or foreign exchange-hence the affinity with the Dutch disease literature. While humanitarian aid falls in this catcgory, reconstruction aid may case supply bottlenecks and increase productivity in the tradable goods sector, and thus affect the recipient economy in a very different way.

dynamics of the economy. As in the rest of the literature, however, this one-off temporary transfer is assumed to be given without regard to the actual state of the recipient economy.

${ }^{7}$ The term was first used to describe the contraction of the tradable goods sector in the Netherlands after the discovery of natural gas and the attendant inflow of foreign exchange. 


\section{The Economics of Post Conflict AID}

In what follows, we build an analytical framework that tries to capture the main features of post conflict aid. We then use it to trace the impact of post conflict aid on capital accumulation, growth, and resource allocation between tradables and non-tradables. The results justify our approach: they are substantially different than those of the traditional aid literature, and furthermore allow us to draw some lessons for the optimal design of post conflict aid.

Our basic model, outlined in the next section, is a dynamic representative agent model based on the work of Brock (1996) and Brock \& Turnovsky (1994) and similar to that used by Obstfeld (1999) and Gong \& Zou (2001). It incorporates three innovations tailored around the stylized facts of post conflict situations.

- Reconstruction aid is included in the production function. One of the main goals of post conflict aid is to rehabilitate the public infrastructure (including public institutions) destroyed during the conflict and restore the provision of essential public services, such as security and order, enforcement of contracts, a functioning legal system, public health, etc. In this way, aid contributes directly to productivity. This adaptation makes our model similar to endogenous growth models that incorporate public spending or, more broadly, the supply of public goods, in the production function.

- Humanitarian aid is distinguished from reconstruction aid. Humanitarian aid-which forms a major part of the overall aid package in the early post conflict period - is different than reconstruction aid: it is intended to support basic consumption needs (food, shelter, medical care) and not production. Our model accounts for this by including humanitarian aid as a consumption transfer alongside reconstruction aid.

- Humanitarian aid is determined by a rule linking the level of aid to the needs of the recipient economy and the generosity of donors. In our model, humanitarian aid is not a permanent income transfer but is disbursed until domestic consumption reaches a certain donor-defined minimum level. Once that is reached, humanitarian aid stops. This rule captures both the nature of humanitarian aid and its distinct time profile observed in post conflict situations.

The following section introduces the basic notation used in our paper, our general model, and the fundamental dynamic optimization methodology. We then develop and solve two variants of the model. The first variant (section B) is a one-good world. We use this variant to explore the impact of the different forms of aid on capital accumulation, growth, and welfare. The second variant (section $\mathrm{C}$ ) is a small open economy, two-good world, in which we examine the impact of reconstruction aid on the real exchange rate and the resource allocation between tradables and non-tradables. The reason for having these two variants is tractability, since solving dynamic optimization problems can quickly get quite complicated. For the same reason, we try to keep the discussion in the following three sections as simple as possible, relegating detailed derivations and proofs to Appendices. 


\section{A. The Basic Model}

Production in the post conflict economy is described by a production function that includes capital, labor, and recostruction aid. ${ }^{8}$ Reconstruction is akin to a public good: foreign aid for reconstruction and institution-building benefit all sectors, but not necessarily to the same extent. ${ }^{9}$

$y=f(k, l, R)$

Reconstruction is not the only form of foreign aid. The other component is humanitarian aid, $H$. One of the distinguishing features of our analysis is the formulation of humanitarian aid. International donors set humanitarian aid according the following simple "graduation" rule:

$$
H=\alpha(\hat{c}-c), \quad 0 \leq \alpha \leq 1
$$

At consumption levels below the donor-defined minimum acceptable consumption $\hat{c}$, the country receives humanitarian assistance. As consumption rises, aid falls until $\hat{c}=c$. At this point, the country stops receiving humanitarian aid and "graduates". The parameter $\alpha$ is very important: it measures the short-run generosity of the donor community. Higher values of $\alpha$ represent higher rates of disbursement of humanitarian aid. If $\alpha=1$, donors are prepared to make immediately available all the necessary resources so that the consumer could consume $\hat{c}$.

Reconstruction aid is assumed to be disbursed at a fixed amount each period for as long as the reconstruction phase lasts. Therefore, in each period, total post conflict aid $D$ is:

$D=H+R=\alpha(\hat{c}-c)+R$

In line with other models of this family, the representative agent is assumed to have an infinite planning horizon and perfect foresight, and to maximize a utility function in terms of consumption $c$ and labor supply $l$. The instantaneous utility function is strictly concave in

\footnotetext{
${ }^{8}$ There are several ways to introduce reconstruction aid into the production function. Here we opt for one of the simplest, in which the flow of reconstruction aid is just another factor of production. This assumption is similar to that in Turnovsky \& Fischer (1995), who examine the impact of public investment on output and capital accumulation.

${ }^{9}$ In most real world cases, reconstruction aid flows through the government sector. Our model can easily be expanded to incorporate a government sector by assuming that $R$ is the amount of public reconstruction spending, which is in turn financed by foreign aid and taxes $R=A+T$. As long as taxes are non-distortionary (a standard assumption) and the government does not borrow, this expansion would add a layer of notation to the model without affecting the results. To keep it simple, therefore, we ignore the government sector.
} 
consumption and labor. We further assume that the marginal utility of consumption is decreasing in labor supply.

The intertemporal optimization problem is set up as a Hamiltonian. The representative agent optimizes this objective function subject to her budget constraint. Derivation of the optimality conditions yields estimates of the instantaneous impact of changes in the exogenous variables such as labor supply, capital accumulation, and consumption. Solution of the dynamic systemprovided it is stable-yields estimates of the impact of changes in the exogenous variables on the steady state equilibrium. In the next two sections, two variants of this basic model are developed and solved. Readers who are not interested in the technical details can skip to the final chapter, which summarizes the results and draws the policy implications.

\section{B. The One-Good Variant}

This variant concentrates on the impact of different forms of post conflict aid on capital accumulation, growth, and welfare. This can best be done in a simple, one-good model. Therefore, the production and utility functions are:

$$
\begin{aligned}
& y=f(R, l, k) \\
& U=\int_{0}^{\infty} u(c, l) e^{-\theta t} d t
\end{aligned}
$$

where $R=$ reconstruction aid, $l=$ labor, and $k=$ capital. The parameter $\theta$ is the agent's rate of time preference. The representative agent's budget constraint is

$c+\dot{k}=f(R, l, k)+\alpha(\hat{c}-c)$

The Hamiltonian problem in the one good model is:

$J=U(c, l) e^{-\theta t}+\lambda e^{-\theta t}(c+\dot{k}-f(R, l, k)-\alpha(\hat{c}-c))$

where $\lambda$ is the co-state variable associated with the budget constraint, and can be intuitively interpreted as the marginal utility of wealth. The first order conditions from optimizing (2.4) are:

$$
\begin{aligned}
& u_{c}=\lambda(1+\alpha) \\
& u_{i}=-\lambda f_{i} \\
& \lambda f_{k}=-\lambda+\theta \lambda
\end{aligned}
$$

and the transversality condition is:

$$
\lim _{t \rightarrow \infty} \lambda k e^{-\theta t}=0
$$


First order conditions (2.5) and (2.6) can be solved for a consumption and a labor supply function:

$$
\begin{aligned}
& c=c(\lambda, k, \alpha, R) \\
& l=l(\lambda, k, \alpha, R)
\end{aligned}
$$

Substituting equations (2.9) and (2.10) into equations (2.3) and (2.7) gives the following dynamic system:

$$
\begin{aligned}
& \dot{\lambda}=\lambda\left(\theta-f_{k}(R, l(\lambda, k, \alpha, R), k)\right) \\
& \dot{k}=f(R, l(\lambda, k, \alpha, R), k)-(1+\alpha) c(\lambda, k, \alpha, R)+\alpha \hat{c}
\end{aligned}
$$

This system describes the dynamic evolution of $k$ and $\lambda$ and determines the intertemporal evolution of the economy as a whole. The steady state is reached when $\dot{\lambda}=\dot{k}=0$.

Denoting the steady state values of $\mathrm{k}$ and $\lambda$ as $k^{*}$ and $\lambda^{*}$ respectively, and linearizing equations (2.11) and (2.12) around these values gives:

$$
\left(\begin{array}{l}
\dot{k} \\
\dot{\lambda}
\end{array}\right)=\left(\begin{array}{cc}
q_{11} & q_{12} \\
-\lambda^{*} q_{21} & -\lambda^{*} q_{22}
\end{array}\right)\left(\begin{array}{l}
k-k^{*} \\
\lambda-\lambda^{*}
\end{array}\right)
$$

where:

$$
\begin{array}{ll}
q_{11}=f_{k}+f_{l} l_{k}-(1+\alpha) c_{k}>0 & q_{12}=f_{l} l_{\lambda}-(1+\alpha) c_{\lambda}>0 \\
q_{21}=f_{k l} l_{k}+f_{k k}<0^{10} & q_{22}=f_{k l} l_{\lambda}>0
\end{array}
$$

This system has a saddle point equilibrium (for proof, see Appendix I), and the general form of the solution is:

$$
\begin{aligned}
& k=k^{*}+A_{1} e^{\phi_{1} t}+A_{2} e^{\phi_{2} t} \\
& \lambda=\lambda^{*}-\frac{\lambda^{*} q_{11}}{\lambda^{*} q_{22}+\phi_{1}} A_{1} e^{\dot{\phi}_{1} t}-\frac{\lambda^{*} q_{21}}{\lambda^{*} q_{22}+\phi_{2}} A_{1} e^{\phi_{2} t}
\end{aligned}
$$

\footnotetext{
${ }^{10}$ If we make the reasonable assumption that $f_{k k}<-f_{k l} l_{k}$.
} 
where $\phi_{1}$ and $\phi_{2}$ are the positive and negative eigenvalues, respectively, and $A_{1}$ and $A_{2}$ are constants determined by the initial conditions and the transversality condition. Substituting these into (2.15) gives:

$$
\begin{aligned}
& k(t)=k^{*}+\left(k_{0}-k^{*}\right) e^{\phi t} \\
& \lambda(t)=\lambda^{*}-\frac{\lambda^{*} q_{21}}{\lambda^{*} q_{22}+\phi_{1}}\left(k_{0}-k^{*}\right) e^{\phi t}
\end{aligned}
$$

As usual, there are two saddle paths, one stable $\lambda-\lambda^{*}=-\frac{\lambda^{*} q_{21}}{\lambda^{*} q_{22}+\phi_{1}}\left(k-k^{*}\right)$ and one unstable $\lambda-\lambda^{*}=-\frac{\lambda^{*} q_{21}}{\hat{\lambda}^{*} q_{22}+\phi_{2}}\left(k-k^{*}\right)$.

\section{The impact of aid on capital accumulation and growth}

In order to examine the impact of humanitarian aid on the steady state equilibrium, we need to differentiate equations (2.11) and (2.12) with respect to $\hat{c}$ and $\alpha$.

$$
\begin{aligned}
& \frac{\partial k^{*}}{\partial \hat{c}}=\frac{\alpha q_{11}}{\Phi}<0 \\
& \frac{\partial \lambda^{*}}{\partial \hat{c}}=-\frac{\alpha q_{22}}{\Phi}<0
\end{aligned}
$$

where $\Phi=q_{11} q_{22}-q_{12} q_{21}>0$. Raising the consumption target reduces the steady state capital stock and the marginal utility of wealth. As the marginal utility of wealth falls, consumption increases and savings fall. In the long run, the steady state capital stock is reduced.

The relationship between $\alpha$ and the steady state equilibrium is more complicated, but provided that $(\hat{c}-c)>0$, the results are similar to those above (for proof, see Appendix II).

$$
\begin{aligned}
& \frac{\partial k^{*}}{\partial \alpha}=\frac{q_{22}}{\Phi}\left((1+\alpha) c_{\alpha}+\left(\frac{q_{12}}{q_{22}} f_{k l}-f_{l}\right) l_{\alpha}-(\hat{c}-c)\right)<0 \\
& \frac{\partial \lambda^{*}}{\partial \alpha}=-\frac{q_{21}}{\Phi}\left((1+\alpha) c_{\alpha}+\left(\frac{q_{11}}{q_{21}} f_{k l}-f_{l}\right) l_{\alpha}-(\hat{c}-c)\right)<0
\end{aligned}
$$


The intuition behind these results is straightforward. Humanitarian aid raises permanent income, and the representative agent can achieve her desired level of consumption with a lower capital stock. Therefore, humanitarian aid unambiguously reduces the steady state capital stock and steady state growth.

The impact of reconstruction aid on the steady state capital stock is:

$$
\frac{\partial k^{*}}{\partial R}=\frac{-q_{22}}{\Phi}\left((1+\alpha) c_{R}+\frac{q_{12}}{q_{22}} f_{k R}-\frac{q_{12}}{q_{22}}\left(f_{l}-f_{k l}\right) l_{R}-f_{R}\right)
$$

The sign of this derivative is ambiguous. However, we can decompose it into four components.

- $\quad$ The direct effect $-f_{R}$. The higher the marginal productivity of reconstruction aid, the smaller the impact of additional reconstruction aid on the steady state capital stock.

- The consumption effect $(1+\alpha) c_{R}$. The agent is willing to sacrifice present consumption for higher future consumption due to the higher marginal product of capital resulting from reconstruction aid.

- $\quad$ The labor supply effect $-q_{12}\left(f_{t}-f_{k l}\right) l_{R} / q_{22}$. This effect also consists of two components with opposite signs. On one hand, higher reconstruction aid increases labor supply, and the same level of output can be achieved with a lower level of capital. On the other hand, higher labor supply increases the marginal product of capital, and therefore tends to raise the steady state capital stock.

- The marginal productivity of capital effect $q_{12} f_{k R} / q_{22}$. Reconstruction aid increases the marginal product of capital and therefore increases the steady state capital stock.

On this basis, it appears that the overall impact of reconstruction aid on the steady state capital stock would tend to be positive unless reconstruction aid induced such a large increase in labor supply and its marginal productivity was so large compared to the other factors of production that the desired consumption level could be achieved with a lower steady state level of capital stock.

\section{The impact of aid on welfare}

The results above could be seen as an argument against humanitarian aid: after all, this form of aid unambiguously reduces long-run capital accumulation and growth. This criticism, however, would be misplaced. Humanitarian aid is not motivated by the desire to boost investment and long-run growth but by the wish to address urgent basic human needs under often tragic circumstances. What matters, therefore, is its impact on welfare. 
On this score, both forms of post conflict aid perform well. If we denote by $W$ the representative agent's overall level of welfare over her infinite time horizon

$W=\int_{0}^{\infty} U_{t} e^{-\theta t} d t$

then Appendix III proves that:

$$
\begin{aligned}
& \frac{d W}{d \alpha}=\frac{u_{c}(\hat{c}-c)}{\theta(1+\alpha)}>0 \\
& \frac{d W}{d \hat{c}}=\frac{u_{c} \alpha}{\theta(1+\alpha)}>0 \\
& \frac{d W}{d R}=\frac{u_{c} f_{R}}{\theta(1+\alpha)}>0
\end{aligned}
$$

Despite the negative impact of increased humanitarian aid on capital accumulation, increased values of $\alpha, \widehat{c}$, as well as $R$, raise the welfare of the representative agent. Humanitarian aid, in particular, increases consumption directly, thereby allowing the representative agent to achieve a given level of consumption with a lower labor supply.

\section{The Two-Good Variant}

This variant of our basic model focuses on the impact of post conflict aid on the real exchange rate and the allocation of resources in the rccipicnt economy between tradable and non-tradable goods. Since humanitarian aid in post conflict economies is typically short-lived, we can simplify the model by setting $H=0$ and concentrating on the effects of reconstruction aid. Because reconstruction aid improves directly productivity in the recipient economy, its effects on the steady state equilibrium are bound to be different than the traditional aid literature suggests. For simplicity, we also fix total labor supply and normalize to unity. Using $T, N$ to denote tradables and non-tradables, respectively, the production and utility functions become:

$$
\begin{aligned}
& y_{i}=f_{i}\left(R, k_{i}, l_{i}\right), i=T, N \\
& U=\int_{0}^{+\infty} u\left(c_{Y}, c_{N}\right) e^{-\theta t} d t
\end{aligned}
$$

For tractability, we assume a multiplicative separable form of the above neoclassical production function, and (3.1) is simplificd to:

$$
\begin{aligned}
& y_{T}=A_{f}(R) f\left(k_{T}, l_{T}\right) \\
& y_{N}=A_{N}(R) h\left(k_{N}, l_{N}\right)
\end{aligned}
$$


where $k=k_{T}+k_{N}, l_{T}+l_{N}=1$, and $A_{i}(R)(i=T, N)$ is a factor that captures the efficiency gains from post conflict reconstruction and institution-building. This is the standard form used in the endogenous growth literature to reflect the function of public goods in production. Note that reconstruction aid need not benefit both sectors equally. Indeed the difference between $A_{T}$ and $A_{N}$ is critical for the results of this variant of the model, and will inform the conclusions on the optimal design of reconstruction aid. We assume that the tradable goods sector is more capital intensive than the non-tradable goods sector $\left.\left(\frac{k_{T}}{l_{T}}\right\rangle \frac{k_{N}}{l_{N}}\right)$ and that capital is non-tradable. Finally, since this is an open economy model, we need to introduce an additional tradable asset (bonds $b$ ) so as to allow the domestic consumption of tradables to be different than the domestic production (in other words, for the current account deficit to be different than zero, at least temporarily).

With these simplifying assumptions, this variant of our model has become very close to the model used by Brock \& Turnovsky (1994) and Brock (1996), and the solution henceforth follows their work. Recalling that $H=0$, the Hamiltonian for this variant can be written as

$J=u\left(c_{\eta}, c_{N}\right) e^{-\theta t}+\lambda e^{-\theta t}\left(c_{T}+c_{N}+\dot{b}+p \dot{k}-A_{T}(R) f\left(k_{T}, l_{N}\right)-p A_{N}(R) h\left(k_{N}, l_{T}\right)-r b\right)$

where $p$ is the real exchange rate (relative price of non-tradables).

The optimality conditions are:

$$
\begin{aligned}
& u_{c_{T}}=\lambda \\
& u_{c_{N}}=\lambda p \\
& A_{T} f_{k}=p A_{N} h_{k}=r \\
& A_{T} f_{l}=p A_{N} h_{l}=w \\
& \frac{\dot{p}}{p}=r-A_{N} h_{K} \\
& \frac{\dot{\lambda}}{\lambda}=\theta-r
\end{aligned}
$$

It is assumed, as is common practice in the literature, that the marginal utility of wealth remains constant. Consequently $\frac{\dot{\lambda}}{\lambda}=0$, and (3.11) implies that the rate of time preference is equal to the world real interest rate. 
The market clearing conditions for tradable and non-tradable goods are:

$$
\begin{aligned}
& \dot{b}=y_{T}-c_{T}+r b \\
& \dot{k}=y_{N}-c_{N}-R
\end{aligned}
$$

Expression (3.12) states that the rate of accumulation of tradable bonds equals the domestic supply of tradable goods minus the domestic consumption of these goods plus the interest earned on the outstanding stock of the tradable bonds. In other words, (3.12) describes the economy's balance of payments with the rest of the world. Expression (3.13) states that capital accumulation equals the excess of domestic production over domestic consumption of non-tradables plus reconstruction aid. Note that reconstruction aid is akin to a capital good and cannot be used to finance directly the consumption of tradable goods. The representative agent is, of course, able to allocate the extra income generated through reconstruction aid to the consumption of either good or to savings, thereby using reconstruction aid indirectly to achieve higher consumption. This formulation fits exactly the stylized facts in post conflict economies.

The transversality condition is:

$\lim _{t \rightarrow \infty} \lambda b e^{-\theta t}=\lim _{t \rightarrow \infty} \lambda p k e^{-\theta t}=0$

Total differentiation of the optimality conditions (3.6) and (3.7) yields the following partial derivatives:

$$
\begin{aligned}
& \frac{\partial c_{T}}{\partial p}=-\frac{\lambda u_{T N}}{\Psi} \\
& \frac{\partial c_{N}}{\partial p}=\frac{\lambda u_{T T}}{\Psi}<0 \\
& \frac{\partial c_{T}}{\partial \lambda}=\frac{u_{N N}-p u_{T N}}{\Psi}<0 \\
& \frac{\partial c_{N}}{\partial \lambda}=\frac{p u_{T T}-u_{T N}}{\Psi}<0
\end{aligned}
$$

where $\Psi=u_{T V} u_{N N}-u_{T N}^{2}>0$

The sign of (3.15) depends on whether tradables and non-tradables are substitutes $\left(u_{T N}<0\right)$ or complements $\left(u_{T N}>0\right)$ in consumption. The signs of (3.17) and (3.18) are negative on the assumptions that (i) both goods are normal (i.e., a decline in the marginal utility of wealth, which is associated with an increase in wealth, leads to increased consumption of both goods); and (ii) even if $T$ and $N$ are complements, the size of the cross effect $u_{T N}$ is smaller than $u_{T T}$ or $u_{N N}$. 
The optimality conditions can be manipulated to derive a number of standard microeconomic results. First, (3.8) and (3.9) can be solved for $r(p)$ and $w(p)$. It can be shown that a real appreciation (i.e., an increase in the price on non-tradables) leads to a decline in the rate of return to capital:

$r_{p}=\frac{A_{N} h}{\kappa_{N}-\kappa_{T}}$, where $\kappa_{i}$ denotes the capital-labor ratio in sector $i$

$r_{p}\left\langle 0\right.$ since we have assumed $\kappa_{T}>\kappa_{N}$

Second, totally differentiating the optimality conditions (3.8) and (3.9) yields the following partial derivatives:

$$
\begin{aligned}
& \frac{\partial \kappa_{T}}{\partial p}=\frac{A_{N} h}{A_{T} f_{k k}\left(\kappa_{N}-\kappa_{T}\right)}>0 \\
& \frac{\partial \kappa_{N}}{\partial p}=\frac{A_{N} h-A_{N} h_{k}\left(\kappa_{N}-\kappa_{T}\right)}{p A_{N} h_{k k}\left(\kappa_{N}-\kappa_{T}\right)}>0
\end{aligned}
$$

Expressions (3.20) and (3.21) imply that a real exchange rate appreciation increases the capital intensity in both sectors. This is because a real appreciation shifts demand away from the more capital-intensive tradable goods toward the more labor-intensive non-tradable goods, thereby increasing the relative price of labor. Firms in both sectors substitute capital for labor, and the capital-labor ratio increases.

Third, it can be shown that an increase in total capital leads to an expansion of the tradable goods sector and a contraction of the non-tradable goods sector. Recalling that the production functions have been assumed to be separable and that $k_{T}+k_{N}=k$ and $l_{T}+l_{N}=1$, we can write

$$
y_{N}=A_{N} h\left(\kappa_{N}\right) \frac{\left(\kappa-\kappa_{T}\right)}{\left(\kappa_{N}-\kappa_{T}\right)} \text { and } y_{T}=A_{T} f\left(\kappa_{T}\right) \frac{\left(\kappa-\kappa_{T}\right)}{\left(\kappa_{T}-\kappa_{N}\right)}
$$

and therefore the partial derivatives of $y_{\mathrm{N}}$ and $y_{\mathrm{T}}$ with respect to total capital $k$ are

$$
\begin{aligned}
& y_{N k}=\frac{A_{N} h}{\kappa_{N}-\kappa_{T}}<0 \\
& y_{T k}=\frac{A_{T} f}{\kappa_{T}-\kappa_{N}}>0
\end{aligned}
$$


since $\kappa_{T}>\kappa_{N}$. This is the standard Rybszinski theorem: an increase in total capital leads to an expansion of the capital-intensive sector and, because labor is drawn out of the labor-intensive sector, a contraction of the latter.

The dynamics of the system are described by the differential equations (3.10), (3.11), (3.12), and (3.13). This system of equations is block recursive, so we can linearize and solve the system in terms of $p$ and $\kappa$.

$$
\left[\begin{array}{c}
\dot{p} \\
\dot{\kappa}
\end{array}\right]=\left[\begin{array}{cc}
q_{11} & 0 \\
q_{21} & q_{22}
\end{array}\right]\left[\begin{array}{l}
p-p^{*} \\
\kappa-\kappa^{*}
\end{array}\right]
$$

where $q_{11}=r-r_{p}, q_{21}=y_{N_{p}}-c_{N_{p}}$, and $q_{22}=y_{N_{k}}$ and, as before, an asterisk denotes the steady state value of the variable.

The determinant of the coefficient matrix is

$\operatorname{Det}[A]=\left(-\frac{A_{N} h}{\kappa_{N}-\kappa_{T}}+r\right)\left(\frac{A_{N} h}{\kappa_{N}-\kappa_{T}}\right)$

which is negative as long as $\kappa_{T}>\kappa_{N},{ }^{11}$ and the system thus has a saddle point equilibrium.

The two eigenvalues of this dynamic system are $\mu_{1}=q_{22}<0, \mu_{2}=q_{11}>0$ and the solution consistent with the initial conditions and the transversality condition is:

$$
\begin{aligned}
& p(t)=p^{*}-\left(\frac{q_{22}-\mu_{1}}{q_{21}}\right)\left(\kappa_{0}-\kappa^{*}\right) e^{\mu_{1} t} \text { and since } \mu_{1}=q_{22} \Rightarrow p(t)=p^{*} \\
& \kappa(t)=\kappa^{*}+\left(\kappa_{0}-\kappa^{*}\right) e^{\mu_{1} t}
\end{aligned}
$$

Expressions (3.25) and (3.26) show that after a shock, $p$ jumps instantaneously to its new steadystate value while $\kappa$ adjusts gradually.

1 Although in this specification of the model the determinant of the coefficient matrix is negative because $\kappa_{T}>\kappa_{N}$, the stability properties of this dynamic system in general do not depend on the assumption regarding the relative capital intensities of the two sectors. This assumption, however, influences the dynamic adjustment of the system. 


\section{The impact of aid on resource allocation}

This variant of our basic model can be used to explore the impact of aid on long-run resource allocation in the recipient economy. In particular, it allows us to differentiate the equilibrium values of $p$ and $k$ with respect to reconstruction aid $R$.

The equations describing the steady state of the economy are the goods market clearing conditions (3.12) and (3.13) and the factor market clearing conditions (3.8) and (3.9). Totally differentiating these equations and solving the resulting linear system yields the following (for details, see Appendix IV).

$\frac{\partial p^{*}}{\partial R}>0$ and $\frac{\partial k^{*}}{\partial R}</>0$

First, an increase in reconstruction aid leads to a real appreciation. The intuition behind this result is straightforward. On the assumption that the impact of reconstruction aid on the tradable goods sector is relatively higher than on the non-tradable goods sector (in other words, $A_{T}>A_{N}$ ), an increase in reconstruction aid would raise the supply of tradable goods relatively more and thus depress their relative price.

However, the impact of reconstruction aid on the total capital stock is ambiguous. This finding is, of course, consistent with the results of the one-good variant of our model. The two-good variant, however, sheds light on the implications for the output of the two sectors. If reconstruction aid raises the long-run total capital stock then, in line with the standard Rybszinski theorem discussed above, the capital-intensive tradable goods sector would expand at the expense of the non-tradable goods sector (this has also been formally demonstrated in (3.22) and (3.23)). Even if reconstruction lowers the long-run total capital stock, the ultimate effect on the output of tradable goods is unclear: on one hand, the decline in total capital would tend to depress the output of the capital-intensive tradable goods sector; on the other, the share of tradable goods would be boosted by the impact of reconstruction aid on productivity. The net effect would depend on the relative impact of lower capital and that of higher total factor productivity on tradable goods production. Thus, the standard result of the Dutch disease literature that aid reduces the output of the tradable goods sector need not arise in the case of post conflict reconstruction aid.

In the traditional aid literature, the output of tradable goods contracts because higher demand for non-tradables, translated into a real appreciation, pulls labor and capital toward the non-tradable goods sector. In our model, output in both sectors can expand not only through higher employment of capital and labor, but also through productivity gains due to reconstruction aid. Therefore, not only can reconstruction aid benefit directly the tradable goods sector, but the higher demand for non-tradable goods may be met without a (significant) reallocation of labor and capital, thus allowing the tradable goods sector to continue expanding. 
A crucial assumption for the results of the differentiation is the relative size of $A_{T}(R)$ and $A_{N}(R)$, in other words, the impact of reconstruction aid on the two sectors. The results above have been drawn on the assumption that $A_{T}>A_{N}$, or that reconstruction aid benefits the tradable goods sector relatively more than the non-tradable goods sector. This assumption appears to be plausible. The more capital intensive tradable goods sector is usually better placed to benefit from improvements in infrastructure and the provision of better public services. In addition, the tradable goods sector is typically the one that suffers most in a conflict, and can therefore be expected to rebound faster during the post-conflict reconstruction. Nevertheless, in the context of our model, $A_{T}>A_{N}$ is essentially an arbitrary assumption, and a crucial one at that.

In real life however, $A_{T}(R)$ and $A_{N}(R)$ are not exogenously given technologies but depend on the characteristics of the aid package. The post-conflict reconstruction and institution-building activities of donors can be designed so as to benefit the tradable goods sector more. This interpretation allows us to derive lessons for donors.

\section{Conclusions AND LESSONS FOR AID DONORS}

Our point of departure was that post-conflict aid is significantly different than conventional development aid: its goals and the circumstances under which it is disbursed are different; its size and duration are different; and it consists of two distinct parts, humanitarian and reconstruction aid, which have different objectives and time profiles from each other, as well as from conventional development aid. On this basis, we argued that the traditional aid literature does not provide an adequate analytical framework for studying the economics of post-conflict aid, especially given how unreliable the main findings of this literature appear to be.

We thus designed a new analytical framework, based on the solid microfoundations of the dynamic optimization model but incorporating three innovations tailored around the stylized facts of post-conflict aid. We included reconstruction aid in the production function to account for the fact that, by rehabilitating infrastructure and public institutions, post-conflict reconstruction directly affects productivity. We distinguished reconstruction from humanitarian aid to reflect the fact that they have fundamentally different objectives: the former aims at improving the productive capacity while the latter is intended to support basic consumption needs. And we built humanitarian aid around a simple rule that links its disbursement to the needs of the recipient economy and the generosity of donors, and allows it to lapse once minimum consumption levels are met.

This analytical framework provides a wealth of new results that elucidate, supplement, and in some cases overturn the conclusions of the traditional aid literature. First, we find that postconflict humanitarian aid, while certainly welfare enhancing in the short run, does not help capital accumulation in the long run. This finding is perhaps the closest to the traditional aid literature, in which aid in the form of an income transfer tends to be consumed rather than saved.

But reconstruction aid is more complicated. There does not seem to be an unambiguous relationship between reconstruction aid and the steady state capital stock. Our model suggests at 
least four different factors that are at play: (i) the marginal productivity of reconstruction aid; (ii) the impact of reconstruction aid on savings; (iii) the impact of reconstruction aid on the productivity of capital; and (iv) the impact of reconstruction aid on labor supply. The first factor tends to reduce the long-run capital stock when reconstruction aid is present; the second and third factors tend to increase it; and the fourth factor has an ambiguous effect. While this is ultimately an empirical question, our presumption on the basis of these findings is that postconflict reconstruction aid tends to raise the equilibrium capital stock.

These theoretical results call into question the specification of traditional aid-investment-growth empirical studies. Most of these studies estimate a simple regression, in which investment depends on total aid. Our analysis suggests that this may not be appropriate, at least in postconflict cases. Total aid disbursements should be decomposed into two distinct components, humanitarian and reconstruction, since they have opposite effects on investment. Using total aid imposes a potentially significant bias on the empirical specification.

Furthermore, post-conflict reconstruction aid, unlike other forms of aid, need not lead to a contraction of the tradable goods sector. By directly boosting productivity in both sectors and influencing consumption decisions, reconstruction aid may indeed result in a sustained expansion of the tradable goods sector. The concern about Dutch disease arising from aid in the form of income transfers may be less serious in the case of post-conflict economies.

What are the lessons for donors? How should the international community spend its limited aid resources in the next post conflict case? If donors are interested in both the current consumption level and the future economic development of the recipient economy, they are confronted with a dilemma. Allocating the aid resources to humanitarian aid raises welfare but hinders economic development; allocating them to reconstruction aid encourages savings and long-term growth but does not address the recipient country's short-term humanitarian needs.

The answer to this dilemma in each individual post conflict case will, of course, depend on the myriad individual factors at play. But our analysis suggests a few general rules-of-thumb. These are not new: indeed they are common knowledge among experienced aid practitioners. But for the first time, these rules-of-thumb are grounded in solid economic analysis.

- $\quad$ First, sequence aid flows. Humanitarian aid has the greatest welfare impact in the immediate post conflict phase, while reconstruction aid takes time to act (and needs to be designed with care, as we argue below). In the presence of an emergency, when economic activity has virtually stopped, labor resources are dispersed, and the prospects for a quick economic recovery are dim, aid resources are best devoted to humanitarian aid.

- Second, choose carefully the target level of consumption and rate of disbursement of humanitarian aid. Modest consumption targets coupled with fast but short-lived rates of disbursement appear to be the least harmful to long-term economic development. Overly generous or protracted disbursement of humanitarian aid, on the other hand, despite its potential appeal to voters in donor countries, risks creating aid dependency, reducing 
labor supply, and ultimately proving counterproductive. The perpetuation of refugee camps, for example, is a clear case in point. Long-term residents of these camps have all but lost their incentive to work and save.

- Third, design reconstruction aid so as to stimulate the development of the tradable goods sector. Give high priority to infrastructure rehabilitation in areas that will benefit first and foremost tradable activities, such as repairing ports and road networks. Put resources in institutions that boost international trade, such as open and transparent trade regimes and regional trade agreements. Emphasize public services that facilitate private sector development, since it is in the private sector that tradable activities are likely to emerge. Assign lower priority to projects that do not promote the production of tradable goods, such as, for instance, building sports, religious, or cultural facilities. Notwithstanding the undisputed merits of such projects, they are the most likely to lead to distortions in the structure of the recipient economy in the long term. 
Table 1. Aid to Selected Post-Conflict Economies, 1990-99 1/

\begin{tabular}{|c|c|c|c|c|c|c|c|c|c|c|}
\hline & 1990 & 1991 & 1992 & 1993 & 1994 & 1995 & 1996 & 1997 & 1998 & 1999 \\
\hline \multicolumn{11}{|l|}{ Total aid, in percent of GDP } \\
\hline Bosnia and Herzegovina & $\ldots$ & $\ldots$ & $\ldots$ & $\ldots$ & 73.6 & 45.2 & 31.4 & 25.5 & 26.2 & 24.2 \\
\hline Cambodia & 3.7 & 5.6 & 10.4 & 15.2 & 13.6 & 18.9 & 13.4 & 10.8 & 11.7 & 8.9 \\
\hline Rwanda & 11.3 & 18.9 & 17.2 & 18.2 & 94.7 & 54.6 & 33.2 & 12.3 & 17.3 & 19.1 \\
\hline West Bank and Gaza 2/ & $\ldots$ & $\ldots$ & $\ldots$ & $\ldots$ & 15.4 & 13.2 & 15.8 & 14.7 & 11.6 & 11.9 \\
\hline \multicolumn{11}{|c|}{ Total aid, per capita, U.S. dollars } \\
\hline Bosnia and Herzegovina & $\ldots$ & $\ldots$ & $\ldots$ & $\ldots$ & 107 & 271 & 239 & 236 & 238 & 274 \\
\hline Cambodia & 5 & 10 & 21 & 30 & 32 & 52 & 38 & 30 & 29 & 24 \\
\hline Rwanda & 42 & 51 & 48 & 47 & 115 & 110 & 69 & 29 & 43 & 45 \\
\hline West Bank and Gaza & $\ldots$ & $\ldots$ & $\ldots$ & $\ldots$ & 276 & 233 & 263 & 255 & 208 & 221 \\
\hline \multicolumn{11}{|c|}{ Total aid, millions of U.S. dollars } \\
\hline Bosnia and Herzegovina & $\ldots$ & $\ldots$ & $\ldots$ & $\ldots$ & 391 & 924 & 844 & 861 & 898 & 1,063 \\
\hline Cambodia & 42 & 91 & 206 & 306 & 327 & 556 & 422 & 333 & 337 & 279 \\
\hline Rwanda & 291 & 361 & 351 & 356 & 714 & 702 & 467 & 230 & 350 & 373 \\
\hline West Bank and Gaza & $\cdots$ & $\ldots$ & $\ldots$ & $\ldots$ & 612 & 547 & 647 & 654 & 553 & 609 \\
\hline
\end{tabular}

Sources: World Bank, World Development Indicators. The data for West Bank and Gaza are from Fischer, Alonso-Gamo, and von Allmen (2001).

$1 /$ Post-conflict periods in bold.

2/ For West Bank and Gaza, data are for gross national income. 
Table 2. Overall Assistance to South Eastern Europe by Type (1999-2001) 1/

(Millions of euros)

\begin{tabular}{lrrr}
\hline & 1999 & 2000 & 2001 \\
\hline Total assistance to South Eastern Europe & & & \\
Budget support / macro financial assistance & 6,026 & 6,629 & 6,657 \\
Reconstruction / economic development & 1,735 & 923 & 889 \\
Humanitarian assistance & 2,681 & 4,682 & 4,835 \\
Other & 1,344 & 405 & 440 \\
Unallocated & 266 & 605 & 469 \\
& 0 & 13 & 23 \\
\hline
\end{tabular}

Sources: World Bank and European Commission Joint Officc, www.seerecon.org.

1/ Commitment basis. Data collected by a survey compiled October 2001. This report is estimated to capture over 94 percent of the funds committed by donors to the region. 
Table 3. South Eastern Europe - The Stability Pact Quick Start Package

\begin{tabular}{|c|c|c|}
\hline & Millions of Euros & Percent of Total \\
\hline Multisector initiatives & 5 & 0.3 \\
\hline Anticorruption initiative & 2 & 0.1 \\
\hline Trauma and reconciliation in South Eastern & 3 & 0.1 \\
\hline Social development initiative & 1 & 0.0 \\
\hline Democratization and human rights & 255 & 14.3 \\
\hline Refugees & 218 & 12.2 \\
\hline Human rights and minorities & 7 & 0.4 \\
\hline Good governance & 3 & 0.2 \\
\hline Public administration & 2 & 0.1 \\
\hline Local government & 1 & 0.1 \\
\hline Ombudsman & 0 & 0.0 \\
\hline Gender & 1 & 0.1 \\
\hline Media & 12 & 0.7 \\
\hline Other & 14 & 0.8 \\
\hline Parliamentary exchange & 1 & 0.0 \\
\hline Education & 12 & 0.6 \\
\hline Szeged process & 2 & 0.1 \\
\hline Reconstruction, development, and cooperation & 1,449 & 81.1 \\
\hline Infrastracture & 1,131 & 63.3 \\
\hline Private sector development & 290 & 16.2 \\
\hline Investment compact & 2 & 0.1 \\
\hline Environment & 20 & 1.1 \\
\hline Vocational education and training & 7 & 0.4 \\
\hline Regional security & 78 & 4.4 \\
\hline Defense and security & 67 & 3.8 \\
\hline Justice and home affairs & 11 & 0.6 \\
\hline lotal & 1,787 & 100.0 \\
\hline
\end{tabular}

Sources: World Bank and European Commission Joint Office, www.seerecon.org. 


\section{Proof of Saddle-Point Equilibrium of the One-Good Dynamic System}

From equation (2.13), define $A=\left(\begin{array}{cc}q_{11} & q_{12} \\ -\lambda^{*} q_{21} & -\lambda^{*} q_{22}\end{array}\right)$

If the characteristic equation of $\mathrm{A}$ has real roots, of which one is positive and the other is negative, then there is a saddle-point equilibrium. Let the characteristic roots of A be $\phi_{1}, \phi_{2}$.

$\phi_{1}, \phi_{2}=\frac{\operatorname{Tr}[A] \pm \sqrt{(\operatorname{Tr}[A])^{2}-4 \operatorname{Det}[A]}}{2}$

If $\sqrt{(\operatorname{Tr}[A])^{2}-4 \operatorname{Det}[A]}>0$ then $\phi_{1}, \phi_{2}$ are real. Expanding

$$
(\operatorname{Tr}[A])^{2}-4 \operatorname{Det}[A]=\left(q_{11}-q_{22} \lambda^{*}\right)^{2}-4 \lambda^{*}\left(q_{12} q_{21}-q_{11} q_{22}\right)=q_{11}^{2}-4 q_{12} q_{21} \lambda^{*}+2 q_{12} q_{21} \lambda^{*}+q_{22}^{2}
$$

This expression simplifies to:

$$
(\operatorname{Tr}[A])^{2}-4 \operatorname{Det}[A]=\left(q_{11}+q_{22} \lambda^{*}\right)^{2}-4 \lambda^{*} q_{12} q_{21}
$$

If $4 \lambda^{*} q_{12} q_{21}<0$ then $(\operatorname{Tr}[A])^{2}-4 \operatorname{Det}[A]>0$ and therefore the roots are real.

$$
\begin{array}{ll}
q_{12}=f_{l} l_{\lambda}-(1+\alpha) c_{k}>0 & \text { Since } f_{l}>0, l_{\lambda}>0, \text { and } c_{k}<0 . \\
q_{21}=f_{k l} l_{k}+f_{k k}<0 & \text { Provided that } f_{k k}>f_{k l} l_{\lambda} \text { (see footnote 10). }
\end{array}
$$

If $\operatorname{Det}[A]<0$ then one root is negative and the other is positive. Note that:

$$
\operatorname{Det}[A]=-\lambda^{*}\left(q_{11} q_{22}-q_{12} q_{21}\right)
$$

First note that $-q_{12} q_{21}>0$. Moreover:

$$
\begin{array}{ll}
q_{11}=f_{k}+f_{l} l_{k}-(1+\alpha) c_{k}>0 & \text { Since } f_{l}>0 \quad f_{l}>0, l_{k}>0 \text { and } c_{k}<0 . \\
q_{22}=f_{l k} l_{\lambda}>0 & \text { Since } f_{l k}>0 \text { and } l_{\lambda}>0
\end{array}
$$

Therefore $\left(q_{11} q_{22}-q_{12} q_{21}\right)>0$ and $\operatorname{Det}[A]=-\lambda^{*}\left(q_{11} q_{22}-q_{12} q_{21}\right)<0$ 


\section{The Impact of $\alpha$ on the Steady State Equilibrium}

The sign of equations (2.20) and (2.21), repeated below

$$
\begin{aligned}
& \frac{\partial k^{*}}{\partial \alpha}=\frac{q_{22}}{D}\left((1+\alpha) c_{\alpha z}+\left(\frac{q_{12}}{q_{22}} f_{k i}-f_{l}\right) l_{\alpha}-(\hat{c}-c)\right)<0 \\
& \frac{\partial \lambda^{*}}{\partial \alpha}=-\frac{q_{21}}{D}\left((1+\alpha) c_{\alpha}+\left(\frac{q_{11}}{q_{21}} f_{k l}-f_{l}\right) l_{\alpha \alpha}-(\hat{c}-c)\right)<0
\end{aligned}
$$

depends on the sign of the expression below:

$q_{22}(1+\alpha) c_{\alpha}+\left(q_{12} f_{k l}-q_{22} f_{l}\right) l_{\alpha}-q_{22}(\hat{c}-c)$

Assuming that $(\hat{c}-c)>0$, then $d k^{*} / d \alpha<0$ if

$q_{22}(\hat{c}-c)>q_{22}(1+\alpha) c_{\alpha}+\left(q_{12} f_{k 1}-q_{22} f_{1}\right) l_{\alpha}$

This can be simplified to

$$
(\hat{c}-c)>(1+\alpha) c_{\alpha}+\left(\frac{q_{12}}{q_{22}} f_{k l}-f_{l}\right) l_{\alpha}
$$

Substituting out $c_{\alpha}$ and $l_{\alpha}$, this expression becomes

$$
(\hat{c}-c)>\frac{(1+\alpha) \lambda f_{l}}{f_{l} u_{c c}+(1+\alpha) u_{c l}}
$$

The numerator of the right-hand side is positive because $f_{l}>0$, but the denominator is negative since $u_{c c}<0$ and $u_{c l}<0$. 


\section{Welfare Analysis}

\section{The impact of $\alpha$ on instantaneous utility}

Let the instantaneous level of utility of the representative agent at time $t$ be $Z(t)$ :

$$
Z(t)=U(c(t), l(t))
$$

The overall level of utility over the agents infinite planning horizon is given by:

$$
W=\int_{0}^{\infty} Z(t) e^{-\theta t} d t
$$

We will analyze the effects of a change in $\alpha$ on the instantaneous utility $Z(t)$ and on the overall welfare $W$. We begin by differentiating $Z(t)$ with respect to $\alpha$.

$$
\frac{d Z(t)}{d \alpha}=u_{c} \frac{d c(t)}{d \alpha}+u_{l} \frac{d l}{d \alpha}
$$

Substituting for $u_{l}$ using the optimality conditions (2.5) and (2.6) yields

$$
\frac{d Z(t)}{d \alpha}=u_{c}\left(\frac{d c(t)}{d \alpha}-\frac{f_{l}}{(1+\alpha)} \frac{d l}{d \alpha}\right)
$$

We proceed by differentiating the market clearing condition $f(k, l, R)+\alpha(\hat{c}-c)=c+\dot{k}+g$. This yields the expression:

$$
\frac{1}{(1+\alpha)}\left[f_{k} \frac{d k}{d \alpha}-\frac{d \dot{k}}{d \alpha}+(\hat{c}-c)\right]=\left[\frac{d c}{d \alpha}-\frac{f_{l}}{(1+\alpha)} \frac{d l}{d \alpha}\right]
$$

Using this expression yields the following expression for $d Z(t) / d \alpha$ :

$$
\frac{d Z(t)}{d \alpha}=\frac{u_{c}}{(1+\alpha)}\left[f_{k} \frac{d k}{d \alpha}-\frac{d \dot{k}}{d \alpha}+(\hat{c}-c)\right]
$$

By substituting the expression corresponding to the dynamic evolution of capital, we obtain the following expression for $d Z(t) / d \alpha$ :

$$
\frac{d Z(t)}{d \alpha}=\frac{u_{c}}{(1+a)}\left[\left(f_{k}\left(1-e^{\phi_{1} t}\right)+\phi_{1} e^{\phi_{1} t}\right) \frac{d k^{*}}{d \alpha}+(\hat{c}-c)\right]
$$


From this, we can derive the impact of a change in $\alpha$ on instantaneous utility:

$\frac{d Z(0)}{d \alpha}=\frac{u_{c:}}{(1+\alpha)}\left[\phi_{1} \frac{d k^{*}}{d \alpha}+(\hat{c}-c)\right]$

as well as the impact of a change in $\alpha$ on the steady-state value of $Z{ }^{12}$

$\frac{d Z^{*}}{d \alpha}=\frac{u_{C}}{(1+\alpha)}\left[f_{k} \frac{d k^{*}}{d \alpha}+(\hat{c}-c)\right]$

\section{The impact of $\alpha$ on total welfare}

A linear approximation to the overall welfare can be obtained by using the expression describing the behavior of $Z(t)$ at the neighborhood of the steady state:

$Z(t)=Z^{*}+\left(Z(0)-Z^{*}\right) e^{\phi_{1} t}$

Substituting this into the definition of welfare and integrating yields:

$W=\frac{Z^{*}}{\theta}-\frac{Z(0)-Z^{*}}{\phi_{1}-\theta}$

This equation corresponds to the linear approximation of total welfare. Differentiating with respect to $\alpha$ yields:

$$
\frac{d W}{d \alpha}=\frac{1}{\theta}\left[\frac{d Z^{*}}{d \alpha}\right]-\frac{1}{\phi_{1}-\theta}\left[\frac{d Z(0)}{d \alpha}-\frac{d Z^{*}}{d \alpha}\right]
$$

Since around the steady-state $f_{k}=\theta$,

$$
\frac{d W}{d \alpha}=\frac{u_{c}(\hat{c}-c)}{\theta(1+\alpha)}>0
$$

This expression represents the total impact of an in increase in $\alpha$ in total welfare.

\footnotetext{
${ }^{12}$ At the neighborhood of the steady state, the terms corresponding to the dynamic evolution of the system are zero.
} 


\section{The impact of $\hat{c}$ on instantaneous utility}

By differentiating $Z(t)$ with respect to $\hat{c}$ and using the optimality conditions we obtain

$$
\frac{d Z(t)}{d \hat{c}}=u_{c}\left(\frac{d c(t)}{d \hat{c}}-\frac{f_{I}}{(1+\alpha)} \frac{d l}{d \hat{c}}\right)
$$

Differentiation of the market clearing condition $f(k, l, R)+\alpha(\hat{c}-c)=c+\dot{k}+g$ yields:

$$
\frac{1}{(1+\alpha)}\left[f_{k} \frac{d k}{d \hat{c}}-\frac{d \dot{k}}{d \hat{c}}+\alpha\right]=\left[\frac{d c}{d \hat{c}}-\frac{f_{l}}{(1+\alpha)} \frac{d l}{d \hat{c}}\right]
$$

Using this expression yields the following expression for $d Z(t) / d \hat{c}$ :

$$
\frac{d Z(t)}{d \hat{c}}=\frac{u_{c}}{(1+\alpha)}\left[f_{k} \frac{d k}{d \hat{c}}-\frac{d \dot{k}}{d \hat{c}}+\alpha\right]
$$

By substituting the expression corresponding to the dynamic evolution of capital, we obtain the following expression for $d Z(t) / d \hat{c}$ :

$$
\frac{d Z(t)}{d \hat{c}}=\frac{u_{c}}{(1+a)}\left[\left(f_{k}\left(1-e^{\phi_{1} t}\right)+\phi_{1} e^{\phi_{1} t}\right) \frac{d k^{*}}{d \hat{c}}+\alpha\right]
$$

From this, we can derive the impact of a change in $\hat{c}$ on instantaneous utility:

$$
\frac{d Z(0)}{d \hat{c}}=\frac{u_{c}}{(1+\alpha)}\left[\phi_{1} \frac{d k^{*}}{d \hat{c}}+\alpha\right]
$$

as well as the impact of a change in $\hat{c}$ on the steady-state value of $Z$.

$$
\frac{d Z^{*}}{d \hat{c}}=\frac{u_{C}}{(1+\alpha)}\left[f_{k} \frac{d k^{*}}{d \hat{c}}+\alpha\right]
$$

\section{The impact of $\hat{c}$ in total welfare}

Differentiating the definition of welfare with respect to $\hat{c}$ yields: 
$\frac{d W}{d \hat{c}}=\frac{1}{\theta}\left[\frac{d Z^{*}}{d \hat{c}}\right]-\frac{1}{\phi_{1}-\theta}\left[\frac{d Z(0)}{d \hat{c}}-\frac{d Z^{*}}{d \hat{c}}\right]$

Since around the steady-state $f_{k}=\theta$

$\frac{d W}{d \hat{c}}=\frac{u_{c} \alpha}{\theta(1+\alpha)}>0$

This represents the total impact of an in increase in $\hat{c}$ in total welfare.

\section{The impact of $R$ on instantaneous utility}

By differentiating $Z(t)$ with respect to $\mathrm{R}$ and using the optimality conditions we obtain the following expression.

$\frac{d Z(t)}{d R}=u_{c}\left(\frac{d c(t)}{d R}-\frac{f_{i}}{(1+\alpha)} \frac{d l}{d R}\right)$

We proceed by differentiating the market clearing condition $f(k, l, R)+\alpha(\hat{c}-c)=c+\dot{k}+g$ with respect to $R$ :

$\frac{1}{(1+\alpha)}\left[f_{k} \frac{d k}{d R}-\frac{d \dot{k}}{d R}+f_{R}\right]=\left[\frac{d c}{d R}-\frac{f_{l}}{(1+\alpha)} \frac{d l}{d R}\right]$

Substitution yields the following expression for $d Z(t) / d R$ :

$\frac{d Z(t)}{d R}=\frac{u_{c}}{(1+\alpha)}\left[f_{k} \frac{d k}{d R}-\frac{d \dot{k}}{d R}+f_{R}\right]$

Using the equation corresponding to the dynamic evolution of capital, we obtain the following expression for $d Z(t) / d R$ :

$\frac{d Z}{d R}=\frac{u_{c}}{(1+a)}\left[\left(f_{k}\left(1-e^{\phi^{\prime} t}\right)+\phi_{1} e^{\phi_{i} t}\right) \frac{d k^{*}}{d R}+f_{R}\right]$

From this, we can derive the impact of a change in $R$ on instantaneous utility:

$\frac{d Z(0)}{d R}=\frac{u_{c}}{(1+\alpha)}\left[\phi_{1} \frac{d k^{*}}{d R}+f_{R}\right]$ 
as well as the impact of a change in $R$ on the steady-state value of $Z$ :

$\frac{d Z^{*}}{d R}=\frac{u_{C}}{(1+\alpha)}\left[f_{k} \frac{d k^{*}}{d R}+f_{R}\right]$

\section{The impact of $R$ on total welfare}

Differentiating the definition of welfare with respect to $R$ yields:

$\frac{d W}{d R}=\frac{1}{\theta}\left[\frac{d Z^{*}}{d R}\right]-\frac{1}{\phi_{1}-\theta}\left[\frac{d Z(0)}{d R}-\frac{d Z^{*}}{d R}\right]$

Since around the steady-state $f_{k}=\theta$,

$\frac{d W}{d R}=\frac{u_{c} f_{R}}{\theta(1+\alpha)}>0$

This expression represents the total impact of an in increase in $R$ in total welfare. 


\section{The Impact of $R$ on Resource Allocation}

Totally differentiating the equations describing the steady-state of the economy we get the following system.

$$
\left[\begin{array}{cccc}
0 & \left(r_{p}-r\right) & 0 & 0 \\
\frac{\partial y_{N}}{\partial k} & \left(\frac{\partial y_{N}}{\partial p}-\frac{\partial c_{N}}{\partial p}\right) & 0 & \frac{\partial c_{N}}{\partial \hat{\lambda}} \\
\frac{\partial y_{T}}{\partial k} & \left(\frac{\partial y_{T}}{\partial p}-\frac{\partial c_{T}}{\partial p}\right) & r & \frac{\partial c_{T}}{\partial \lambda} \\
p_{0} & 0 & 1 & 0
\end{array}\right]\left[\begin{array}{c}
d \dot{k} / d R \\
\dot{*} / d R \\
d \dot{b} / d R \\
\dot{*} / d R
\end{array}\right]=\left[\begin{array}{c}
-\frac{\partial r}{\partial R} \\
\left(1-\frac{\partial y_{N}}{\partial R}\right) \\
\frac{\partial y_{T}}{\partial R} \\
0
\end{array}\right]
$$

This system can be solved using Cramer's rule, and we obtain:

$$
\begin{aligned}
& \left.\frac{d \dot{k}}{d R}=\frac{\left(r_{p}-r\right)\left[\left(1-\frac{\partial y_{N}}{\partial R}\right) \frac{\partial c_{T}}{\partial \lambda}-\left(\frac{\partial y_{T}}{\partial R} \frac{\partial c_{N}}{\partial \lambda}\right)\right]}{D}\right]_{/<0} \\
& \frac{d^{*} p}{d R}=\frac{\left[r p_{0}\left(\frac{\partial r}{\partial R} \frac{\partial c_{N}}{\partial \lambda}\right)\right]+\frac{\partial r}{\partial R}\left[\frac{\partial y_{N}}{\partial k} \frac{\partial c_{T}}{\partial \lambda}-\frac{\partial y_{T}}{\partial k} \frac{\partial c_{N}}{\partial \lambda}\right]}{D}>0
\end{aligned}
$$

where

$$
D=\left|\begin{array}{cccc}
0 & \left(r_{p}-r\right) & 0 & 0 \\
\frac{\partial y_{N}}{\partial k} & \left(\frac{\partial y_{N}}{\partial p}-\frac{\partial c_{N}}{\partial p}\right) & 0 & \frac{\partial c_{N}}{\partial \lambda} \\
\frac{\partial y_{T}}{\partial k} & \left(\frac{\partial y_{T}}{\partial p}-\frac{\partial c_{T}}{\partial p}\right) & r & \frac{\partial c_{T}}{\partial \lambda} \\
p_{0} & 0 & 1 & 0
\end{array}\right|>0
$$




\section{References}

Brock, P.L., 1996, "International Transfers, the Relative Price of Non-Traded Goods and the Current Account," Canadian Journal of Economics, Vol. 29, No. 1, pp. 63-80.

and S.J. Turnovsky, 1994, "The Dependent-Economy Model with Both Traded and Non-Traded Capital Goods," Review of International Economics, Vol. 2, pp. 306-25.

Bulír, A., and A. J. Hamann, 2001, "How Volatile and Unpredictable Are Aid Flows, and What Are the Policy Implications?" IMF Working Paper 01/167 (Washington: International Monetary Fund).

Burnside, C., and D. Dollar, 2000, "Aid, Policies and Growth," American Economic Review, Vol. 90, No. 4, pp. 847-68.

Collier, P., 1999, "On the Economic Consequences of War," Oxford Economic Papers, Vol. 51, pp. $168-83$.

Demckas, D.G., J. Herderschee, and D. Jacobs, 2002, Kosovo: Institutions and Policies for Reconstruction and Growth (Washington: International Monetary Fund).

Dollar, D., and W. Easterly, 1999, "The Search for the Key: Aid Investment and Policies in Africa," Journal of African Economics, Vol. 8, No. 4, pp. 546-77.

Easterly, W., 1999, "The Ghost of Financing Gap: Testing the Growth Models Used in Financial Institutions," Journal of Development Economics, Vol. 60, pp. 423-38.

Fischer, S., P. Alonso-Gamo, and U. Erickson von Allmen, 2001, "Economic Development in the West Bank and Gaza since Oslo,” Economic Journal, 111, pp. F254-75.

Gang, I. N., and H. A. Khan, 1991, "Foreign Aid, Taxes, and Public Investment," Journal of Development Economics, Vol. 34, pp. 355-69.

Gong, L., and H. Zou, 2001, "Foreign Aid Reduces Labor Supply and Capital Accumulation," Review of Development Economics, Vol. 5, pp. 105-18.

Hansen, H., and F. Tarp, 2000, "Policy Arena Aid Effectiveness Disputed," Journal of International Development, Vol. 12, pp. 375-98.

,2001, "Aid and Growth Regressions," Journal of Development Economics, 64, pp. $547-70$.

Hjertholm, P., J. Laursen, and H. White, 2000, "Macroeconomic Issues in Foreign Aid," University of Copenhagen, Institute of Economics, Discussion Paper. 
Keynes, J.M., 1929, “Mr. Keynes' Views on the Transfer Problem," Economic Journal, 39 (155), pp. 388-408.

Krugman, P., 1987, "The Narrow Moving Band, the Dutch Disease, and the Competitive Consequences of Mrs. Thatcher," Journal of Development Economics, Vol. 27, pp. $41-55$.

Lensink, R., and O. Morrissey, 2000, "Aid Instability as a Measure of Uncertainty and the Positive Impact of Aid on Growth," Journal of Development Studies, Vol. 36, No. 3, pp. $31-49$.

McGillivray, M., 2000, "Aid and Public Sector Behavior in Developing Countries," Review of Development Economics, Vol. 4, No. 2, pp. 156-63.

, and O. Morrissey, 2001, "Aid Illusion and Public Sector Fiscal Behavior," Journal of Development Studies, Vol. 37, pp. 118-36.

Michaely, M., 1981, "Foreign Aid, Economic Structure and Dependence," Journal of Development Economics, Vol. 9, pp. 313-30.

Obstfeld, M., 1999, "Foreign Resource Inflows, Savings and Growth," The Economics of Savings and Growth, ed. by K. Schmidt-Hebbel, and L. Serven (Cambridge: Cambridge University Press).

Ohlin, B.G., 1929, "Transfer Difficulties, Real and Imagined," Economic Journal, Vol. 39, pp. $172-8$.

Otim, S, 1996, "Foreign Aid and Government Fiscal Behaviour in Low-Income South Asian Countries," Applied Economics, Vol. 28, pp. 927-93.

Pigou, A.C., 1932, "The Effect of Reparations on the Ratio of International Interchange," Economic Journal, 42, pp. 532-43.

Rattsø, J., and Torvik, R., 1999, "The Macroeconomics of Foreign Aid in Sub-Saharan Africa: Dutch Disease Effects Reconsidered," Foreign Aid: New Perspectives, ed. by K.L. Gupta (Boston: Kluwer Academic Publishers).

Turnovsky, S.J., 1995, Methods of Macroeconomic Dynamics (Cambridge, Massachusetts.: MIT Press).

, 1996, "Endogenous Growth in a Dependent Economy with Traded and NonTraded Capital," Review of International Economics, Vol. 4, No. 3, pp. 300-21. 
Turnovsky, S.J., and W.H. Fischer, 1995, "The Composition of Government Expenditure and its Consequences for Macroeconomic Performance," Journal of Economic Dynamics and Control, Vol. 19, pp. 747-86.

Van Wijnbergen, S., 1986, "Macroeconomic Aspects of the Effectiveness of Foreign Aid: the Two Gap Model, Home Goods Disequilibrium and the Real Exchange Rate Misalignment," Journal of International Economics, Vol. 21, pp. 123-36.

White, H., 1992, "The Macroeconomic Impact of Development Aid: A Critical Survey," The Journal of Development Studies, Vol. 28, No. 2, pp. 163-240.

World Bank, 2001, World Development Indicators (Washington: World Bank). 